\title{
Физико-химический и механический состав почвы виноградников, обогащенной энергетическим биоматериалом
}

\author{
Татьяна Николаевна Воробьева, д-р с.-х. наук; \\ Валерий Семенович Петров, д-р c.-х. наук, toksikolog@mail.ru \\ Алексей Сергеевич Белков, аспирант, belkov_aleksei86@mail.ru; \\ Антон Владимирович Прах, канд. с.-х. наук. \\ Федеральное государственное бюджетное научное учреждение «Северо-Кавказский федеральный научный центр садоводства, \\ виноградарства, виноделия», Россия, 350901, г. Краснодар, ул.Им. 40-лет. Победы, 39
}

Растительные отходы сельскохозяйственного производства в основном утилизируются в качестве кормов в животноводстве и реже используются в виде удобрения на многолетних насаждениях. Из растительных сельскохозяйственных отходов в качестве органического удобрения могут быть использованы вторичные отходы винодельческого производства, виноградные выжимки. Обоснование возможности применения такого вида биоудобрения в конкретных условиях с учетом показателей, характеризующих биоматериал и состав почвы, послужило целью выполненной работы. Биогенность деградируемой почвы ампелоценозов увеличивается легко гидролизируемыми виноградными выжимами, по своему биохимическому составу являющимися зональным экологическим индукторам физико-химического и механического состава почвы. Партии используемого биоматериала, вносимого в почву опытных участков в период проводимых исследований, по своим биохимическим показателям (азот, фосфор, калий, органическое вещество, $\mathrm{pH}$ ) не имели существенных различий. Показатели содержания подвижных форм фосфора и калия в почве используют для оценки фосфатного и калийного режимов разных почв. При их недостаточности в почве рациональна замена агрохимикатов, относящимся к средствам химизации сельского хозяйства (фосфор-калийные удобрения), биоудобрением из отходов виноградовинодельческого производства, содержащим эти макроэлементы. Определено, что повышение биогенности и физико-химического состава почвы возможно обогащением ее отходами виноделия, содержащими питательные вещества для корнеобитаемого слоя почвы (азот 6,3\%; фосфор 0,44\%; калий $1,59 \%)$, органическое вещество до $82 \%$ и рН не вызывающий изменений кислотного баланса почвы. Установлено, что после одного цикла (весна-осень-весна 2017-2018 гг.) внесения биоудобрения в комплексе с эффективными микроорганизмами (препарат Байкал ЭМ-1) почва характеризовалась увеличением органического вещества на 0,3\%, подвижных форм фосфора - на 11,0 мг/кг, общего азота - на 0,07\%, макроэлементов кальция, натрия, магния, калия - от 2,0 до 7,0 мг/кг, уменьшением гранулометрического состава почвы (фракция < 0,01 мм) - на 0,7\%, снижением концентрации тяжелых металлов (кобальт, мышьяк, медь, цинк - по ГОСТ) - от 0,1 до 6,0 мг/кг. Использование виноградных выжимок в комплексе с эффективными микроорганизмами в качестве энергетического биоматериала удовлетворяет современным требованиям эколого-экономической и эффективной утилизации растительных отходов сельского хозяйства в области виноградовинодельческого производства.

Ключевые слова: виноградник; почва; биоудобрение; виноградные выжимки; эффективные микроорганизмы.
O R I G I N A L A R T I C L E

\section{Soil physico-chemical and mechanical composition in the vineyards enriched with energy biomaterial}

Tatyana Nikolaievna Vorobyova, Valeriy Semionovich Petrov, Aleksey Sergeevich Belkov, Anton Vladimirovich Prah

Federal State Budget Scientific Institution North Caucasian Federal Scientific Centre of Horticulture, Viticulture, Winemaking (FSBSI NCFSCHVW), 39, 40 let Pobedy STR., 350901, Krasnodar, Russia

Vegetation residue from agricultural production is mainly used as feed in livestock rearing, and is less frequently used as fertilizer on perennial plantings. From agricultural green waste, secondary waste from wine production and grape pomace can also be used as organic fertilizers. We conducted feasibility studies on the use of such bio-fertilizers under specific conditions, taking into account soil composition and biomaterial parameters. Biogenesity of the degrading soils of ampelocenoses can be improved by easily hydrolyzed grape marc, the biochemical composition of which serves as zonal ecological inducer of soil physico-chemical and mechanical composition. Batches of biomaterial introduced into soil of experimental plots during research had no significant differences in biochemical parameters (nitrogen, phosphorus, potassium, organic matter, $\mathrm{pH}$ ). Active forms of phosphorus and potassium content in the soil is used to estimate the phosphate and potassium statuses of different soils. When their content in the soil is insufficient, it is recommended to replace the agrochemicals (phosphorus-potassium fertilizers) with bio-fertilizers from grape-growing production waste rich in those macronutrients. The study established that soil biogenisity and physico-chemical composition can be improved through its enrichment with winemaking waste containing nutrients for soil root layer (nitrogen $4.3 \%$; phosphorus $0.49 \%$; potassium $1.49 \%$ ), up to $82 \%$ of organic matter and the $\mathrm{pH}$ that does not alter the soil acid balance. It was found that one cycle (spring-autumn - spring 2017-2018) of biofertilizer introduction combined with effective microorganisms (Baikal EM-1 preparation), increased organic matter in the soil by $0.3 \%$, active phosphorus by $11.0 \mathrm{mg} / \mathrm{kg}$, total nitrogen by $0.07 \%$, calcium, sodium, magnesium, and potassium macronutrients from 2.0 up to $7.0 \mathrm{mg} / \mathrm{kg}$, and decreased soil granulometric composition (fraction $<0.01 \mathrm{~mm}$ ) by $0.7 \%$; it decreased heavy metal concentration (cobalt, arsenic, copper, zinc - under GOST) from 0.1 to $6.0 \mathrm{mg} / \mathrm{kg}$. Combined application of grape pomace and effective micro-organisms as energy biomaterial meets modern requirements for environmentally sound, effective and efficient disposal of agricultural green waste material in the field of viticulture.

Key words: vineyard, soil, bio-fertilizer, grape pomace, effective microorganisms.

\section{Как цитировать эту статью:}

Воробьева Т.Н., Петров В.С., Белков А.С., Прах А.В. Физико-химический и механический состав почвы виноградников, обогащенной энергетическим биоматериалом // «Магарач». Виноградарство и виноделие, 2019; 21(2); C. 128-132. DOI 10.35547/IM.2019.21.2.010

To cite this article:

Vorobyova T.N., Petrov V.S., Belkov A.S., Prah A.V. Soil physico-chemical and mechanical composition in the vineyards enriched with energy biomaterial. Magarach. Viticulture and Winemaking; 2019; 21(2); pp. 128-132. DOI 10.35547/IM.2019.21.2.010

удК 634.8.047:631.442/.46

Поступила 27.01.2019

Принята к публикации 16.05 .2019

(C) Авторы, 2019 


\section{ВИНОГРАДАРСТВО}

Физико-химический и механический состав почвы винограАников, обогащенной энергетическим биоматериалом
Воробьева Т.Н., Петров В.С.,

Белков А.С., Прах А.В.
$\mathrm{B}$ ведение. Процесс окультуривания и жесткая эксплуатация виноградных насаждений привоАит к потере необходимого Аля почвы энергетического потенциала: активного гумуса, природной почвенной микрофморы, естественной структуры и т.А. [1-4]. Аля повышения низкого биологического потенциала почвы необходимо восстановцение ее физико-химического состава, что возможно Аостичь обогащением почвы энергетическим биоматериалом в виде гумифицированных растительных остатков в комплексе с эффективными микроорганизмами (Байкац ЭМ-1) [5-8].

Органические вещества гумифицированных растительных остатков, разцагаясь, обеспечивают почву питательными веществами, такими как азот, фосфор и калий, которые поглощаются растениями и служат удобрением виноградной мозы. С Аругой стороны, содержание в почве органики сдерживает вымывание питательных веществ, что улучшает структуру почвы удерживанием воды, снижающей потенциал ее упцотнения [9-16].

Источники питательных веществ гумифицированных растительных остатков, являясь средой обитания полезных микроорганизмов, конкурируют с болезнетворными организмами и повышают функции биологической активности почвы [17-20].

В мировой практике имеют место исследования по использованию виноградных выжимок винодельческого произвоАства ААя повышения плоАородия почвы, продуктивности растений и качества продукции. При этом очевиАно, что желаемый результат зависит от множества факторов, основой которых явцяются взаимосвязь биохимических показателей преАлагаемого биоматериала и физико-химического состава почвы. Поэтому обоснование применения энергетического биоматериала в качестве выжимок винограда, Аополненных эффективными микроорганизмами, в конкретных условиях, с учетом показателей, характеризующих используемый биоматериал и состав почвы, послужимо целью выполненной работы.

Объекты и методы иссмедований. Исследования проводились на виноградных насаждениях гибридов красных сортов Тана 85/42 и Тана 68/33 технического направления использования в условиях полевого мелкоделяночного опыта (ОПХ «Центральное» г. КрасноAар.). Схема посадки $3 \times 1,5$ м, формировка - обратный оАноплечий корАон, площадь питания $4,5 \mathrm{~m}^{2}$, насажАения 2013 г. Размер делянки 6 × 30 м² Защитные полосы - 1 м. ОАноименные делянки каждого варианта име$\Lambda и$ Аве повторности. ЗакмаАка мабораторно-полевого опыта проводикась по утвержденным методикам [21].

Используемый материал - почва, винограА, выжимки виноградовинодельческого производства, эффективные микроорганизмы.

Отбор проб аля определения структуры, механических и физико-химических свойств почвы провоАился в соответствии с ГОСТ (17.4.3.01-83; 17.4.4.0284; 28168-89) и РА 39-0147098-015-90. Отобранные пробы почвы подготовмены и проанацизированы согласно ГОСТ (12536-79; 26213-91; 26483-85). Валовое содержание тяжелых метамлов опредемянось измере- ниями массовой Аоли кислот растворимых форм металмов (меди, свинца, цинка, никеля, кадмия) на атомно-абсорбционном спектрофотометре «Квант-АФА» (РА 52.18.191-89). Физико-химический и механический состав почвы определялся: «Практикум по Почвоведению» Москва «Колос», 1980 г. ( суспензии по ГОСТ 26423-85, нитратный азот Аисумьфофеноловым методом, подвижный фосфор $\left(\mathrm{P}_{2} \mathrm{O}_{5}\right)$ и калий $\left(\mathrm{K}_{2} \mathrm{O}\right)$ (по Мачигину) ГОСТ 26205-91, содержание гумуса - по ГОСТ 26213-91, опредемение нитратов ионометрическим методом (ГОСТ 26951-86). Используемые приборы и оборудование - атомно-абсорбционный спектрофотометр «Квант-АФА», колориметр фотоэлектрический КФК-2, рефрактометр RL3, электронные весы HL-300 WP.

А^я обработки экспериментацьного материала использовали программы (Microsoft Excel 2016; Statistica 6.0 for Windows).

Обсуждение результатов. Оздоровление почвы и повышение ее биологической активности возможно с помощью различного вида агробиоремедиационных мероприятий, основанных на применении биопрепаратов, сорбентов, индукторов супрессивности или аккумуляторов загрязняющих веществ. [22-25]. При остром Аефиците органики, чем характеризуется почва виноградных насаждений, в качестве индукторов физико-химических свойств, перспективным направцением явмяется использование энергетического биоматериала вторичных отходов виноградовинодельческого производства.

Исследования Проводились по следующей схеме опыта: 1 вариант - без внесения биоудобрения (контроль); 2 вариант - внесение биоудобрения обогащенного препаратом Байкац ЭМ-1.

Биоудобрение по всем вариантам опыта было внесено в почву виноградников опытного участка весной (апрель), осенью (октябрь) и весной (апрель). Отбор проб аля анализа проводимся из одной партии, гАе выжимка сохранялась примерно в одинаковом микрокмимате.

Биохимический анализ виноградных выжимок, подготовменных к использованию Аля внесения в почву виноградников, показац степень их пригодности по показателям $\mathrm{pH}$ водной вытяжки, элементов питания и степень гумификации по содержанию органического вещества. Значения $\mathrm{pH}$ водной вытяжки биоматериала и обследуемой почвы были близки по показателям, это не повлечет изменений кислотного баланса почвы. Использование гумифицированных виноградных выжимок в комплексе с эффективными микроорганизмами (препарат Байкац ЭМ-1) позвоцяет повысить в почве содержание макроэлементов и органического вещества, недостающих Аля корнеобитаемого слоя почвы и растения (табл.1).

ПреАставцены показатели физико-химического и механического состава почвы после одного цикма внесения (весна-осень 2017 г. и весна 2018 г.). Приготовленный рабочий раствор препарата Байкац ЭМ-1 вносился одновременно с виноградными выжимками. Отбор проб почвы проводикся переА очередным внесением биоудобрения (табц. 2). 
Таблица 1. Биохимический анализ виноградных выжимок (мелкоделяночный полевой опыт)

Table 1. Biochemical analysis of grape marc (micro-plot field experiment)

\begin{tabular}{|c|c|c|}
\hline \multirow{2}{*}{$\begin{array}{l}\text { Показатель } \\
\text { (единицы измерения) }\end{array}$} & \multicolumn{2}{|c|}{ Срок отбора проб } \\
\hline & апре ь & октябрь \\
\hline pH водной вытяжки (еА. pH) & $7,3 \pm 0,33$ & $7,1 \pm 0,30$ \\
\hline $\begin{array}{l}\text { Азот общий на исх. вАажность } \\
(\%)\end{array}$ & $6,0 \pm 0,32$ & $6,4 \pm 0,35$ \\
\hline $\begin{array}{l}\text { Общий фосфор на } \\
\text { исх. вмажность }(\%)\end{array}$ & $0,44 \pm 0,015$ & $0,43 \pm 0,016$ \\
\hline $\begin{array}{l}\text { Общий камий на } \\
\text { исх. вцажность (\%) }\end{array}$ & $1,54 \pm 0,06$ & $1,61 \pm 0,07$ \\
\hline Органическое вещество (\%) & 77 & 82 \\
\hline
\end{tabular}

Таблица 2. Влияние биоудобрения на физикохимический и механический состав почвы (2018 г.)

Table 2. The effect of bio-fertilizer on soil physical, chemical and mechanical composition (2018)

\begin{tabular}{|c|c|c|c|}
\hline $\begin{array}{l}\text { Показатель } \\
\text { (еАиницы измерения) }\end{array}$ & $\begin{array}{l}\text { Контромь } \\
\text { апре ьь/ок- } \\
\text { тябрь }\end{array}$ & $\begin{array}{l}\text { Внесение } \\
\text { биоудобре- } \\
\text { ния (апремь) }\end{array}$ & $\begin{array}{l}\text { Внесение } \\
\text { биоудобре- } \\
\text { ния (ок- } \\
\text { тябрь) }\end{array}$ \\
\hline pH водной вытяжки & $6,9 \pm 0,33$ & $7,1 \pm 0,29$ & $7,0 \pm 0,22$ \\
\hline $\mathrm{pH} \mathrm{KCL}$ & $6,1 \pm 0,41$ & $6,0 \pm 0,34$ & $6,1 \pm 0,44$ \\
\hline $\begin{array}{l}\text { Сумма погмощенных } \\
\text { оснований, } \\
\text { ммомь } / 100 \text { г }\end{array}$ & $21,6 \pm 0,51$ & $22,8 \pm 0,72$ & $23,6 \pm 0,69$ \\
\hline Органическое в-во (\%) & $3,3 \pm 0,18$ & $3,5 \pm 0,25$ & $3,8 \pm 0,36$ \\
\hline $\begin{array}{l}\text { Пнотный остаток во- } \\
\text { Аной вытяжки } \\
\text { (сумма токсичных во- } \\
\text { Аорастворимых сомей) } \\
(\%), \text { мг/кг }\end{array}$ & $\begin{array}{l}<0,1(0,04) \% \\
400 \mathrm{мг/кг}\end{array}$ & $\begin{array}{l}<0,1(0,04) \% \\
400 \mathrm{мг/кг}\end{array}$ & $\begin{array}{l}<0,1(0,04) \% \\
400 \mathrm{мг/кг}\end{array}$ \\
\hline Общий азот (\%) & $0,17 \pm 0,009$ & $0,22 \pm 0,009$ & $0,25 \pm 0,011$ \\
\hline $\begin{array}{l}\text { Аммонийный азот } \\
(\mathrm{Mr} / к \Gamma)\end{array}$ & $12,2 \pm 0,73$ & $14,7 \pm 0,64$ & $13,8 \pm 0,70$ \\
\hline $\begin{array}{l}\text { Нитратный азот } \\
(\mathrm{Mr} / \mathrm{k})\end{array}$ & $37,2 \pm 0,63$ & $40,1 \pm 0,83$ & $40,4 \pm 0,85$ \\
\hline $\begin{array}{l}\text { Сульфат ион } \\
\text { (водн. выт.) } \\
(\mathrm{Mr} / \mathrm{k})\end{array}$ & $97 \pm 0,85$ & $99 \pm 0,71$ & $98 \pm 0,79$ \\
\hline $\begin{array}{l}\text { Подвижный фосфор } \\
\left(\mathrm{P}_{2} \mathrm{O}_{5}\right)(\mathrm{мг} / \mathrm{kг})\end{array}$ & $263 \pm 1,09$ & $276 \pm 0,87$ & $274 \pm 0,91$ \\
\hline $\begin{array}{l}\text { Подвижный камий } \\
\left(\mathrm{K}_{2} \mathrm{O}\right)(\mathrm{Mr} / \mathrm{\kappa г})\end{array}$ & $438 \pm 1,06$ & $452 \pm 1,21$ & $458 \pm 1,23$ \\
\hline Карбонатность & некарбонатнаs & я, не вскипает & от $\mathrm{HCl}$ \\
\hline 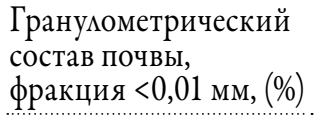 & $24,7 \pm 0,41$ & $23,9 \pm 0,26$ & $23,2 \pm 0,33$ \\
\hline $\begin{array}{l}\text { Кмассификация по- } \\
\text { чвы по Качинскому, } \\
\text { на основании фрак- } \\
\text { ции <0,01 мм, } \\
\text { (физическая глина) }\end{array}$ & \multicolumn{3}{|c|}{ Сугминок мегкий } \\
\hline
\end{tabular}

Эффективность биоудобрения отмечалась уже после 2-кратного внесения (апремь и октябрь 2017 г/) увеличением органического вещества на $0,3 \%$, подвижных форм фосфора на 11,0 мг/кг, общего азота -
Таблица 3. Валовое содержание тяжелых металлов в почве виноградников после внесения биоудобрения (октябрь 2018 г.)

Table 3. Gross content of heavy metals in the soil of the vineyards after introduction of bio-fertilizer (October 2018)

\begin{tabular}{|c|c|c|c|}
\hline $\begin{array}{l}\text { Показатемь } \\
\text { (единицы } \\
\text { измерения) }\end{array}$ & $\begin{array}{l}\text { Без внесения биоудо- } \\
\text { брения (контромь) }\end{array}$ & $\begin{array}{l}\text { Внесение } \\
\text { биоудобрения }\end{array}$ & ПАК \\
\hline Кобамьт (мг/кг) & $7,6 \pm 0,05$ & $7,2 \pm 0,04$ & 12,0 \\
\hline Мышьяк (мг/кг) & $3,9 \pm 0,05$ & $3,5 \pm 0,07$ & 6,0 \\
\hline $\operatorname{Me}_{A b}(м г / к г)$ & $28,3 \pm 0,30$ & $26,9 \pm 0,70$ & 55,0 \\
\hline Цинк (мг/кг) & $97 \pm 0,63$ & $91 \pm 0,61$ & 100,0 \\
\hline Кадмий $(м г / к г)$ & $0,08 \pm 0,015$ & $<0,05$ & 5,0 \\
\hline Ртуть (мг/кг) & $<0,05$ & $<0,05$ & 2,1 \\
\hline
\end{tabular}

на 0,07\%; макроэлементов кацьция, натрия, магния, калия - от 2,0 Ао 7,0 мг/кг. Гранулометрический состав почвы (фракция <0,01 мм) уменьшимся на $0,7 \%$. После 3-кратного внесения биоудобрения (апрець и октябрь 2017 г., апремь 2018 г.) разцичия в полученных Аанных (октябрь 2018 г.) были незначительными, возможно питательные эмементы послужики удобрением

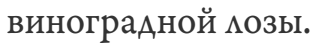

Вацовое содержание в почве токсичных элементов тяжелых метацмов до внесения биоудобрения не превышало Аопустимых норм. После внесения представменного в исследованиях цикма комплексного биоудобрения концентрация тяжелых метамлов (кобамьт, мышьяк, меАь, цинк - по ГОСТ) в почве уменьшимась от 0,1 Ао 6,0 мг/кг (табц. 3).

Активизация процесса выноса питательных веществ в растение из почвы, обогащенной биоудобрением, подтверждена показатемями биохимического анализа виноградного сусла (табл. 4).

Внесение в почву органического удобрения отмечалось увецичением концентрации сахаров в образцах опытных участков. На основные вкусовые качества винодецьческой продукции вцияют винная, яблочная и $и$ ионная кислоты, обнаруживаемые во всех органах винограда. Они находятся и в корнях растения, с обимьно представ енной зАесь Аимонной кислотой. Кислоты могут быть в свободном виде и в составе сомей, образуемых основаниями, извлекаемыми из почвы. Эти минерацьные вещества особенно важны Аця роста винограда.

В экстремацьных погодных условиях периода вегетации 2018 г. урожайность гибридов красных сортов на опытном участке была на 1,7 ц/га выше в сравнении с контрольным вариантом.

Выводы. УАучшение физико-химического состава почвы внесением энергетического биоматериала, состоящего из виноградных выжимок и эффективных микроорганизмов, подтвержАается полученными экспериментацьными Аанными выполненных исследований:

- увеличением содержания макро- и микроэлементов - подвижных форм фосфора на 60,0 мг/кг, общего азота - на 0,06\%; кацьция, натрия, магния, камия - от 2 
Таблица 4. Биохимический состав сусла винограда при внесении комплексного биоудобрения (урожай 2018 г.)

Table 4. Grape must biochemical composition after introduction of complex bio-fertilizers (harvest of 2018)

\begin{tabular}{|c|c|c|c|c|c|c|c|}
\hline Комментарий & Брикс & Т.к. & Винная кислота & Ябцочная кислота & Янтарная кислота & Аимонная кислота & Уксусная кислота \\
\hline $\begin{array}{l}\text { Внесение } \\
\text { биоудобрения }\end{array}$ & $20,2 \pm 0,30$ & $8,5 \pm 0,27$ & $5,68 \pm 0,24$ & $2,77 \pm 0,26$ & $0,05 \pm 0,002$ & $0,16 \pm 0,003$ & $0,15 \pm 0,003$ \\
\hline $\begin{array}{l}\text { Без внесения } \\
\text { биоудобрения } \\
\text { (контроць) }\end{array}$ & $19,4 \pm 0,33$ & $8,0 \pm 0,37$ & $5,36 \pm 0,18$ & $2,52 \pm 0,23$ & $0,05 \pm 0,003$ & $0,14 \pm 0,002$ & $0,17 \pm 0,003$ \\
\hline
\end{tabular}

Ао 9 мг/кг, органического вещества - на 0,3\% и уменьшением на $0,7 \%$ структуры почвы;

- уменьшением концентрации валового содержания тяжемых метамлов (кобацьт, мышьяк, меАь, цинк) от 0,1 но 6 мг/кг;

- повышением пищевой ценности виноградного сырья по биохимическим показателям (концентрация сахаров и органических кислот) Аця винодемия;

- повышением урожайности на 1,7 ц/га в сложившихся экстремацьных погодных условиях вегетационного периода 2018 г.

Использование виноградных выжимок удовлетворяет современным требованиям эколого-экономической и эффективной утимизации растительных отходов семьского хозяйства в обцасти виноградовиноАемьческого производства.

\section{Источник финансирования}

Не указан.

\section{Financing source}

Not specified.

\section{Конфликт интересов}

Не заявцен.

\section{Conflict of interests}

\section{Not declared.}

\section{Список литературы / References}

1. Воробьева, Т. Н. Экологическая проблема промышленного виноградарства / Т. Н. Воробьева // Плодоводство и виноградарство Юга России. ФГБНУ СКФНЦСВВ. Краснодар 2016. №39(03). - C.87-89.

Vorobyeva T.N. Ekologicheskaya problema promyshlennogo vinogradarstva. Plodovodstvo i vinogradarstvo Yuga Rossii. FGBNU SKFNCzSWV. Krasnodar [Fruit growing and viticulture of the South of Russia. GNU SPNZSW]. Krasnodar. 2016. №39(03) P. 87-89. (in Russian)

2. Руи Казар, Д. Внедрение технологии прямого посева / Д. Руи Казар // Аграрный консультант, № 2, 2011. - С.11-14.

Rui Kazar D. Vnedrenie texnologii pryamogo poseva [Introduction of technology of direct seeding] //Agrarnyj konsultant [Agricultural consultant]. No. 2, 2011. P. 11-14. (in Russian)

3. Trofano, J. Effect of simulated acidic rain on retention of pesticides on leaf surfaces /J. Trofano, E.J. Butterfield // Phytopathology. 1984.- Vol. 74. - N 11. - P. 1377-1380.

4. A Practical Guide to the Application of Compost in Vineyards - Fall. Travis, J., et al. http://www.ritlee.co.za/compost/compost vinyards.pdf.2003.

5. Воробьева, Т.Н. Механизмы биотрансформации деградируемой почвы ампелоценозов / Т. Н. Воробьева, В. С. Петров // Плодоводство и виноградарство Юга России. - Краснодар: ФГБНУ СКФНЦСВВ, 2018.

Vorobyeva T.N., Petrov V.S. Mehanizmy biotransformacii degradiruemoj pochvy ampelocenozov [Biotransformation mechanisms of degraded soil ampelocenosis] Plodovodstvo i vinogradarstvo Yuga Rossii. FGBNU SKFNCZSVV [Fruit growing and viticulture of the South
Russia. GNU SPNZSW]. Krasnodar 2018. March. (in Russian)

6. Белков, А.С. Санация деградирующей почвы виноградных насаждений/ А.С. Белков // Субтропическое и декоративное садоводСтво, № 65, 2018. - C. 174-180.

Belkov A.S. Sanaciva degradiruyushbej pochvy vinogradnyx nasazhdenij [Rehabilitation of degraded soil of vineyards] // Subtropicheskoe i dekorativnoe sadovodstvo [Subtropical and ornamental horticulture]. No. 65, 2018. P. 174-180. (in Russian)

7. Воробьева, Т.Н. Способ содержания почвы виноградников / Т.Н. Воробьева, Ю.А. Ветер, А.А. Волкова // Патент РФ № 2531001. М.: ФИПС, 2014. - 4 C.

Vorobyeva T.N., Veter Yu.A., Volkova A.A. Sposob soderzhaniya pochvy vinogradnikov [Way content of soil vineyards] Patent RF № 2531001. [Russian Federation Patent № 2531001]. Moscow: FIPS, 2014. 4 p. (in Russian)

8. Воробьева Т.Н., Агеева Н.М., Прах А.В., Белков А.С. Наш патент № 2661842 Регистрация 19.07.2018 г. «Содержание почвы виноградников».

Vorobyeva T.N., Ageeva N.M., Prax A.V., Belkov A.S. Nash patent № 2661842 Registraciya 19.07.2018. Soderzhanie pochvy vinogradnikov [patent No. 2661842 Check 19.07.2018. Content of soil vineyards]. (in Russian)

9. Киян, А. Т. Ресурсосберегающее производство в виноградарстве на основе новых агроприемов и технологий (исследования, разработка, внедрение) / А.Т. Киян. - Краснодар. - 2004. - 360 с.

Kiyan A.T. Resursosberegayushbee proizvodstvo v vinogradarstve na osnove novyb agropriemov i texnologij (issledovaniya, razrabotka, vnedrenie) [ Resource-Saving production in viticulture on the basis of new agricultural practices and technologies (research, development, implementation). Krasnodar. 2004. p. 360. (in Russian)

10. Belnap J., and D.A. Gillette. 1997. Disturbance of biological soil crusts: impacts on potential wind erodibility of sandy desert soils in southeastern Utah, USA. Land Degradation and Development 8: 355-362.

11. Handelsman, J. Metagenomics application of genomics to uncultured microorganisms / Handelsman, J. // Microbiol. Mol. Biol. 2014. Vol. 68. P. 669-685.

12. Annabi, M., S. Houot, M. Poitrenaud, J.N. Rampon, H. Gaillard, and Y. Le Bissonnais. 2004. Effect of organic amendments on soil aggregate stability. Sustainable Organic Waste Management for Environmental Protection and Food Safety. Ramiran 2004.1:51-54.

13. Eldridge, D.J., E. Zaady, and M. Shachak. 2000. Infiltration through three contrasting biological soil crusts in patterned landscapes in the Negev, Israel. Catena 40: 323-336.

14. Karadimos D.A., Karaoglanidis G.S., Tzavella-Klonari K.: Biological activity and physical modes of actionof Qo inhibitor fungicides trifloxystrobin andpyraclostrobin against Cercosporabeticola. CropProt., 24: 23-29. 2005.

15. Komarek, M.; Cadkova, E.; Chrastny, V.; Bordas, F. \& Bollinger, $\mathrm{J}$-C. Contamination of vineyard soils with fungicides: A review of environmental and toxicological aspects. Environment International. 36; 138-151.2010.

16. Chen S.K., Edwards C.A.: A microcosm approach to assess the effects of fungicides on soil ecological processes and plant growth: compari- 
sons of two soil types. Soil Biol. Biochem., 33: 1981-1991. 2001.

17. Bermudez-Couso, A.; Arias-Estevez, M.; Novoa-Munoz, JC.; LopezPeriago, E.; SotoGonzalez, B. \& Simal-Gandara, J. Seasonal distributions of fungicides in soils and sediments of a small river basin partially devoted to vineyards. Water Research. 41; 4515-4525. (2007).

18. Круглов, Ю.В. Микрофлора почвы и пестициды / Ю.В. Круглов // ВО «Агропромиздат», 1991. - 128 с.

Kruglov, Yu.V. Mikroflora pochvy $i$ pestitsidy. VO "Agropromizdat» [Agropromizdat], 1991. - 128 s. (in Russian)

19. Arias, M.; Lopez, E.; Fernandez, D. \& Soto, B. Copper distribution and dynamics in acid vineyard soils treated with copper-based fungicides. Soil Science. 169; 796-805. (2004).

20. Demenaou J., Monkiedje A., Nin T., Foto S.M., Nola M.Kemka N.: Changes in soil chemical propertiesand microbial activity response to the fungici de Ridomil Gold plus copper. Int. J. Environ. Res. PublicHealth., 1: 26-34. 2004.

21. Доспехов, Б.А. Методика опытного дела / Б.А. Доспехов. - М.: Колос, 1979. - 416 с.

Dospebov B.A. Metodika opytnogo dela [Methodology of experimental work]. Moscow: Kolos, 1979. 416 p. (in Russian)

22. Петров, В.С. Научные основы биологической системы содержания почвы на виноградниках / В.С. Петров. - Новочеркасск, 2003. -170 c.
Petrov V.S. Nauchnye osnovy biologicheskoj sistemy soderzhaniya pochvy na vinogradnikax [The Scientific basis of the biological system of soil maintenance in the vineyard]. Novocherkassk, 2003. 170 p. (in Russian)

23. Тихонович, И.А. Симбиозы растений и микроорганизмов: молекулярная генетика агросистем / И.А. Тихонович, Н.А. Проворов // СПб.: Изд-во С.-Петербургского университета, 2009. - 210 с.

Tixonovich I.A., Provorov N.A. Simbiozy rastenij i mikroorganizmov: mo-lekulyarnaya genetika agrosistem [Symbioses of plants and microorganisms: molecular genetics of agricultural systems]. SPb.: St. Petersburg University publ., 2009. 210 p. (in Russian)

24. Федоров, Л.А. Пестициды - токсический удар по биосфере и человеку / Л.А. Федоров, А. В. Яблоков. - М.: Наука, 1999. - 462 с.

Fedorov L.A., Yablokov A.V. Pesticidy - toksicheskij udar po biosfere $i$ cheloveku [Pesticides - toxic impact on the biosphere and humans]. Moscow. Science, 1999. 462 p. (in Russian)

25. Черников, В.А. Агроэкология / В.А. Черников, Р.М. Алексахин и др. - М.: Колос, 2000. - 536 с.

Chernikov V.A., Aleksaxin R.M. i dr. Agroekologiya [Agroecology]. (in Russian) Moscow: Kolos, 2000. 536 p. (in Russian) 